\title{
Special Issue on "Fundamentals and Numerical Simulations in High-Temperature Corrosion and Protection Focus Issue"
}

\author{
C. Desgranges ${ }^{1,2}$ (D) $\cdot$ B. Pint ${ }^{3} \cdot$ D. Monceau $^{4}$
}

Received: 15 February 2017/Published online: 3 March 2017

(C) Springer Science+Business Media New York 2017

Presented in this focus issue of Oxidation of Metals are key papers that deal with many fundamental aspects associated with the high-temperature corrosion of materials. Such aspects include diffusion, defects, phase transformations, oxygen permeability, volatilization, both short- and long-term behavior, and mechanical properties of the oxide.

Model systems (pure metals or model alloys) are mostly studied. These studies concern various types of systems (chromia-, alumina-, and zirconia-scale forming systems, titanium alloys, and composite materials) with applications extending from nuclear power generation to aeronautics. Special care to design well-controlled experiments is a common thread of the various studies presented. The use of thermodynamics modeling and sometimes kinetics modeling, but also DFT calculations, is a key focus in several papers. Indeed, there is a systematic trend evolving in the community to use various numerical simulations (from atomistic to mesoscopic scale) as powerful tools for understanding the complexity of hightemperature corrosion processes.

C. Desgranges

clara.desgranges@safrangroup.com

B. Pint

pintba@ornl.gov

D. Monceau

daniel.monceau@ensiacet.fr

1 CEA-Saclay, Gif-sur-Yvette Cedex, France

2 Present Address: Safran Paris-Saclay, Rue des Jeunes Bois, Châteaufort, CS 80112, 78772 Magny-Les-Hameaux, France

3 Materials Science and Technology Division, Oak Ridge National Laboratory, Oak Ridge, TN 37831-6156, USA

4 CIRIMAT, CNRS, INP Toulouse, ENSIACET 4 Allée Emile Monso, BP 44362, 31030 Toulouse Cedex 4, France 
The following key papers stem from presentations that were given at the ninth international conference on high-temperature corrosion and protection of materials (HTCPM2016), which was held at Les Embiez Island, France, on the 15-20th of May 2016. 